\title{
自己組織化量子ドットを用いた広帯域スーパールミネッセントダイオードの開発と 光コヒーレンストモグラフィーへの応用
}

\author{
尾崎 信彦 \\ 和歌山大学 システム工学部 ( ₹ 640-8510 和歌山県和歌山市栄谷 930)
}

\section{Development of a Broadband Superluminescent Diode Based on Self-Assembled Quantum Dots for Optical Coherence Tomography Applications}

\author{
Nobuhiko OZAKI \\ Faculty of Systems Eng., Wakayama University, 930 Sakaedani, Wakayama, Wakayama 640-8510
}

(Received June 20, 2019)

\begin{abstract}
This paper reviews a near-infrared (NIR) superluminescent diode (SLD) based on self-assembled InAs quantum dots (QDs). Self-assembled InAs QDs exhibiting a broadband NIR spectrum due to their size and In composite distributions are suitable for optical coherence tomography (OCT) applications. We developed a QD-based SLD (QD-SLD) and demonstrated high-axial-resolution OCT imaging using the QD-SLD. InAs QD layers with controlled emission wavelengths were grown on GaAs, and an edgeemitting SLD with a tilted waveguide and segmented electrodes was fabricated. An electroluminescence spectrum spanning approximately $1-1.3 \mu \mathrm{m}$ with a bandwidth of $144 \mathrm{~nm}$ was obtained, and the inverse Fourier transform of the spectrum predicted an axial-resolution of $3.6 \mu \mathrm{m}$ in air. OCT images of test samples obtained with the QD-SLD actually indicated an axial resolution of $\sim 4 \mu \mathrm{m}$, which is less than that of a conventional OCT $(10-15 \mu \mathrm{m})$. This practical imaging demonstrates the potential of the QDSLD as a high-axial-resolution OCT light source.
\end{abstract}

Key Words: Self-assembled quantum dot, Superluminescent diode, OCT

1. はじめに

近赤外光 (波長約 $0.7 \sim 2.5 \mu \mathrm{m}$ ) は, 光通信やバイオイ メージングなど様々な分野で広く利用されている。特に, 波長 $0.7-1.3 \mu \mathrm{m}$ 程度の領域は「生体の空」と呼ばれ, 生 体の主要な構成元素である血中へモグロビンや, メラニ ン, 水による吸収が少なく, 生体内の透過性が高いこと から医療・生体イメージングに有用な波長带とされる1). この波長帯の光を用いた非侵襲な断層イメージング技術 として, 光コヒーレンストモグラフィー $(\mathrm{OCT})$ が知られ る. OCT は, 1991 年の Huang らによる網膜と冠動脈壁 の in vitro 観察の報告2) 以来, 数年の間に眼科臨床応用 がなされ, 現在では眼科のみならず, 皮膚科, 循環器内 科, 歯科など様々な臨床医学分野に広がっている3-5). また最近では，医療用途のみならず，非破壊検査など産 業用途にも応用が進められている。

OCT はマイケルソン干渉計を基本構成とし, 光源に 広帯域(低コヒーレンス)光を用いた低コヒーレンス光干 渉によってサンプル内部の断層画像取得を可能にする. 詳細な原理は後述するが, OCT の性能を決めるのは主
として光源であり, 特に医療用途には近赤外波長の広带 域光源開発が重要である。これまで様々な OCT 用の光 源開発が進められてきているが，本稿では，その中で半 導体ベースの広帯域光源であるスーパールミネッセント ダイオード (SLD) $\left.{ }^{6,7}\right)$ に焦点を当て, その課題である広 帯域化を実現すべく，我々がこれまで開発してきた自己 組織化 InAs 量子ドット $(\mathrm{QD})^{8)}$ を発光材料とする SLD 光 源 (QD-SLD)を中心に紹介する.

\section{OCT の原理と光源}

OCT には幾つかの画像取得方式があり,ここでは Huang ${ }^{2}$ らによって報告された第一世代の時間領域 (Time-domain: TD)-OCT を基に動作原理を簡単に述べる。 Fig. 1 に示すように, OCT は光干渉計をべースとし, 光 源に低コヒーレンス光を用いる. 光源からの光がビーム スプリッタにより二分岐され，参照ミラーとサンプルに 入射した後，それぞれの反射光が再びビームスプリッ夕 で合波，干渉すると検出器により干渉強度が測定される。 ここで, 低コヒーレンス光の可干渉範囲は, 光源とサン 


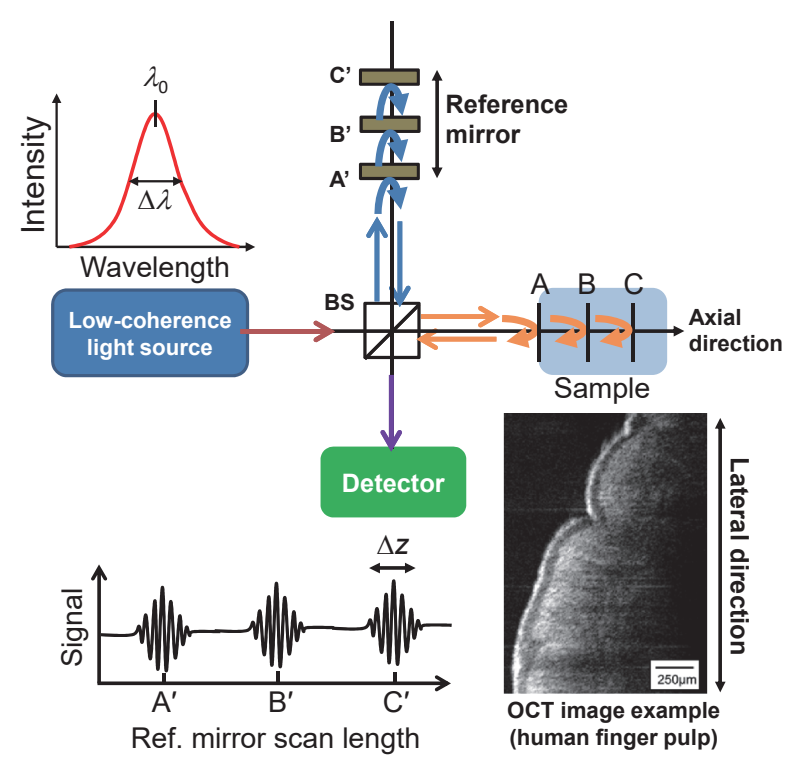

Fig. 1 Schematic image of TD-OCT.

プル間および光源と参照ミラー間の光学距離が等しい位 置から有限の距離 (コヒーレンス長 $: l_{c}$ ) に限定されるた め, サンプル内の光軸上の局所領域の反射強度を計測す ることになる。参照ミラーを軸上で移動させながら干渉 強度を測定すると, サンプル内の光軸上の反射率分布, すなわち反射層の位置を計測でき，光軸をサンプル面内 で走査すれば, 2 次元や 3 次元の OCT 画像が得られる. 得られる画像の光軸方向の分解能 $(\Delta z)$ は, コヒーレンス 長の半分 (反射光路差は光軸上距離の 2 倍) となり, 光源 スペクトルがガウシアン形状の場合, $\Delta z$ は式(1)で表さ れる3)

$$
\Delta z=\frac{2 \ln 2}{\pi} \frac{\lambda_{0}^{2}}{\Delta \lambda} \quad\left(\lambda_{0}: \text { 中心波長, } \Delta \lambda \text { : 帯域幅 }\right)
$$

この式から分かる通り, OCT の光軸分解能は光源の 中心波長と帯域幅に依存し, 中心波長が短い, もしくは 帯域が広い光源が高分解能化に貢献する。医療用 OCT の場合は, サンプル内への浸透長を得るために中心波長 は先述の「生体の空」領域(約 $0.7 \sim 1.3 \mu \mathrm{m}$ ) に設定するこ とが望ましいので, 高分解能化には, この波長帯での帯 域幅の拡大が必要となる。 また, OCTの点拡がり関数 (PSF)は, 光源パワースペクトルのフーリエ変換で得ら れる自己相関関数 (Wiener-Khinchineの定理)によって決 まる3)ため, 光源スペクトル中にディップが存在すると PSF にサイドローブが発生し，画像ノイズの原因とな る9). そのため, スペクトル形状はガウシアンなどの単 峰性形状が望ましい.

TD-OCT の 開 発後, Spectral-domain $(\mathrm{SD})-\mathrm{OCT}^{10)}$ や Swept-source (SS)-OCT ${ }^{11)}$ といった, 多波長の光干渉信号 をフーリエ逆変換によって空間情報に直す Fourierdomain (FD) 方式と呼ばれる OCTが提案された。 TDOCT と比較して, 参照ミラー駆動が不要のため高速で, 感度も 2-3 桁向上できるため, 現在の市販 OCT の主流 となっている. 動作原理については既に優れた解説があ
るので12-14)，詳細はそちらを参考頂きたいが，FD 方式 においても, OCT の光軸分解能 $(\Delta z)$ が光源の中心波長 と帯域に依存することは TD-OCT と同様であり, OCT に適した光源として近赤外波長において広帯域かつスぺ クトル中にディップが少ない光源が求められる.

このような要求に対し, OCT 光源として当初から用 いられたのは半導体ベースの SLD 光源である。しかし ながら，SLDは広帯域化に限界があり，他の選択肢と して様々な広帯域光源(熱光源15,16), fs パルスレー ザー17), Supercontinuum 光源18,19)など)が検討, 開発され, 高分解能化を実現してきている。 これらの光源に対し, SLD は半導体デバイスゆえの軽量・コンパクト, 低コ スト，高信頼性といったメリットがあり，現在も一定の 需要がある. SLDの広帯域化が実現されれば, 半導体 デバイスの利点を活かしながら高分解能 OCT を実現す る光源としての利用価值がある.

\section{3. 自己組織化量子ドットを用いた SLD 光源}

$\mathrm{SLD}^{6,7}$ は通常の半導体レーザー (LD) と同様, p-i-n 接 合内に活性層を埋め込み, 上下クラッド層とリッジ型導 波路などにより形成された導波モード光を端面出射にて 得る。 LD との違いは，端面に反射抑制(AR) コートを施 したり，端面に対する導波路の入射角度を傾斜させるな どして端面反射を低減し，チップ内部でのレーザー発振 を抑制する点である。つまり，光利得による発光増幅は 起こすが，LDのようなコヒーレンス性はわざと低下さ せているため, 高強度な低コヒーレンス光が得られる. この特徵から, SLD は LED と LDの中間の性質を持つ 光源とも言われる. SLD の発光材料は一般的に InGaAsP 系などの半導体量子井戸 $(\mathrm{QW})$ が用いられ, 均一膜厚で ある QW の狭帯域発光特性のため SLD の発光帯域幅が $100 \mathrm{~nm}$ 程度に制限される。そこで，QW を自己組織化 $\mathrm{QD}^{8)}$ に置き換えて広带域化を実現する案が1999年に Sunらによってなされ20)，その後我々を含む多くのグ ループによって開発がなされてきた21-29).

$\mathrm{GaAs}$ 上に InAs をエピタキシャル成長させると，両者 の格子定数差による歪により, 一定の臨界膜厚以上で三 次元 (島状) 成長に転移する $(\mathrm{S}-\mathrm{K} \text { 成長モード })^{8)}$. この島 状の微結晶が自己組織化 QD と呼ばれるものである.
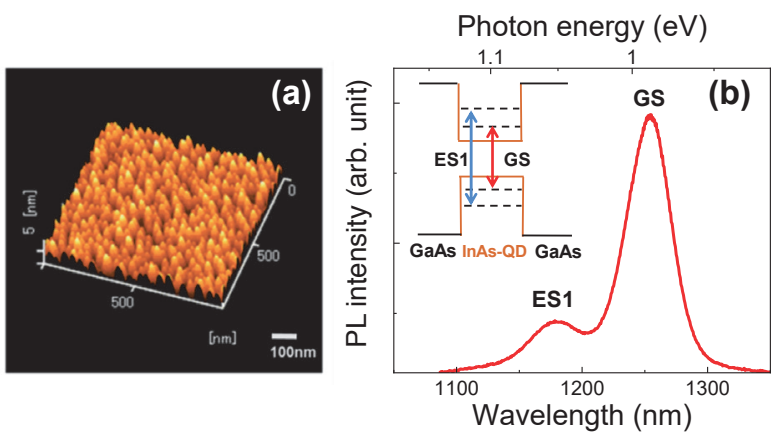

Fig. 2 (a) AFM image and (b) PL spectrum of selfassembled InAs QDs. 
Fig. 2 (a)に, InAs-QD 集合体の分子間力顕微鏡 $(A F M)$ 像 の例を示す．歪誘起によって自然発生的に成長するため, QD 集合体には一定のサイズ分布が発生する。サイズが 異なると量子サイズ効果により QD のバンドギャップエ ネルギーが変化するため, 一定のサイズ分布を持った QDの集合体からは, 広带域な発光が得られる。 GaAs 基板上の InAs-QD は，バンドギャップエネルギーが約 $1 \mathrm{eV}$ (発光波長が $1.2 \sim 1.3 \mu \mathrm{m}$ ) であり, 先述の OCT 光源 への要求を満たす発光材料となる.

また, QD は 3 次元の量子閉じ込め効果により, 離散 的なエネルギー準位を持つ. Fig. 2(b)に QD の室温での PL スペクトルを示すが, QDのバンドギャップエネル ギーに相当する最低次のエネルギー準位 (GS: Ground State) 間の発光と, その上のエネルギー準位である第一 励起準位 (ES1: $1^{\text {st }}$ Excited State) 間の発光が 2 つのピーク として表れている。それぞれのピークは，QD サイズ分 布による広帯域な発光となり, 弱励起状態では GS 間発 光強度が支配的であるが, 励起強度を上げると GS 間発 光強度は飽和し, その後 ES 間発光強度が増大する, QD は QW と比べて GS の状態数が少ないため, 低電流密度 で GS 間発光が飽和し，高次準位間の発光が寄与するた め, 発光帯域が短波長側へ拡大しやすい. 以上のように, 自己組織化 QD は，一定のサイズ分布および高次準位間 発光の寄与により, 広帯域な発光が期待できる。

Fig. 3(a)に，我々が作製した QD-SLD の断面模式図を 示す. 分子線エピタキシー法により, $\mathrm{n}-\mathrm{GaAs}$ 基板上に $\mathrm{p}$-i-n 接合の $\mathrm{GaAs} / \mathrm{AlGaAs}$ 層を積層し, $240 \mathrm{~nm}$ 厚の $\mathrm{GaAs}$ 導波層を $1.5 \mu \mathrm{m}$ 厚の上下クラッド層 $\left(\mathrm{n}-/ \mathrm{p}-\mathrm{Al}_{0.35} \mathrm{Ga}_{0.65} \mathrm{As}\right)$ で挟むことでキャリアおよび光閉じ 込めを行った。導波層内には, 発光波長を制御した InAs-QD を 4 層積層した。 QD の発光波長制御のために,

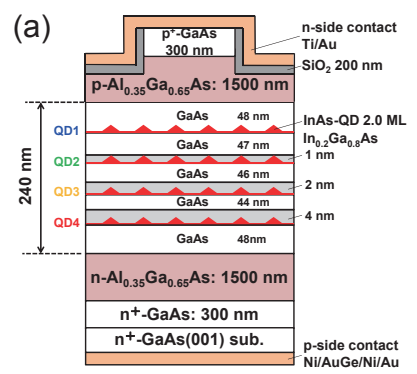

(b)

(c)
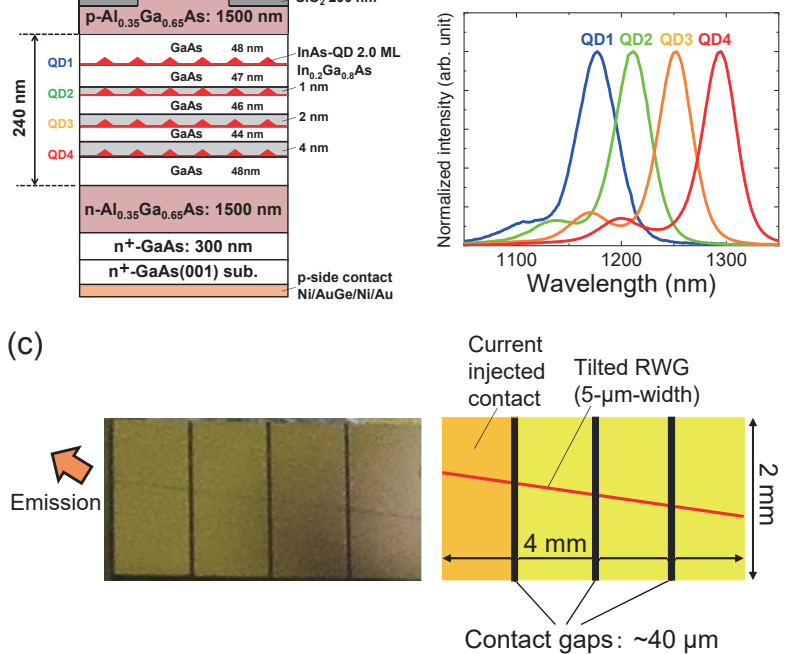

Fig. 3 (a) Schematic profile of a fabricated QD-SLD. (b) PL spectra of QDs with controlled emission peak wavelengths. (c) Plan-view photograph (left) and schematic drawing (right) of the fabricated QDSLD with a tilted RWG and segmented contact electrodes.
歪緩和層 (SRL: Strain-reducing Layer) ${ }^{30)}$ と呼ばれる $\mathrm{In}_{0.2} \mathrm{Ga}_{0.8} \mathrm{As}$ 薄膜を QD と $\mathrm{GaAs}$ スペーサー層との間に異 なる膜厚 $(0 \sim 4 \mathrm{~nm})$ で積層した. SRLはQDにかかる $\mathrm{GaAs}$ からの圧縮応力を低減させ，実効的な QD の量子 閉じ达めサイズを拡大する効果があり，厚みを増やすこ とで連続的な波長シフトが可能となる. SRL 膜厚によ り発光波長を制御した QD からのPL スペクトル例を Fig. 3 (b)に示す。このように QD の中心波長を連続的に シフトさせて積層することで, 更なる発光広帯域化と, $\mathrm{GS}$ 間発光と ES 間発光との間の強度谷間を埋め合わせ た単峰性スペクトルが期待できる24).

この成長基板に対し, 半導体微細加工プロセスでリッ ジ型導波路を形成後, 長さ $4 \mathrm{~mm}$ のチップ状にへき開し, 端面出射型のSLD デバイスとした (Fig. 3 (c) ) . 導波路 はへき開面に対し垂直方向から約 6 度の角度で入射する 斜め導波路とした。また，導波路上に設ける電極は，4 つの領域に分割した構造27) とした。分割電極の出射端 に近い領域にのみ電流を注入し, 電流密度を上げて QD の高次準位発光を促進するとともに，電流を注入しない 領域を光吸収領域としてチップ内のレーザー発振を抑制 し，より広帯域な SLD 特性が得られるよう図った。

Fig. 4(a)にEL スペクトルの例を示す。注入電流量を 増加するにつれ発光波長 $1.2 \sim 1.3 \mu \mathrm{m}$ の GS 間発光強度 は飽和し ES 間発光が寄与するため, 発光ピーク波長は 約 $1.1 \mu \mathrm{m}$ にブルーシフトし，帯域は $144 \mathrm{~nm}$ が得られた この EL スペクトルをフーリエ変換して得られた自己相 関関数を Fig. 4(b) に示す。半值全幅は $3.6 \mu \mathrm{m}$ となり,
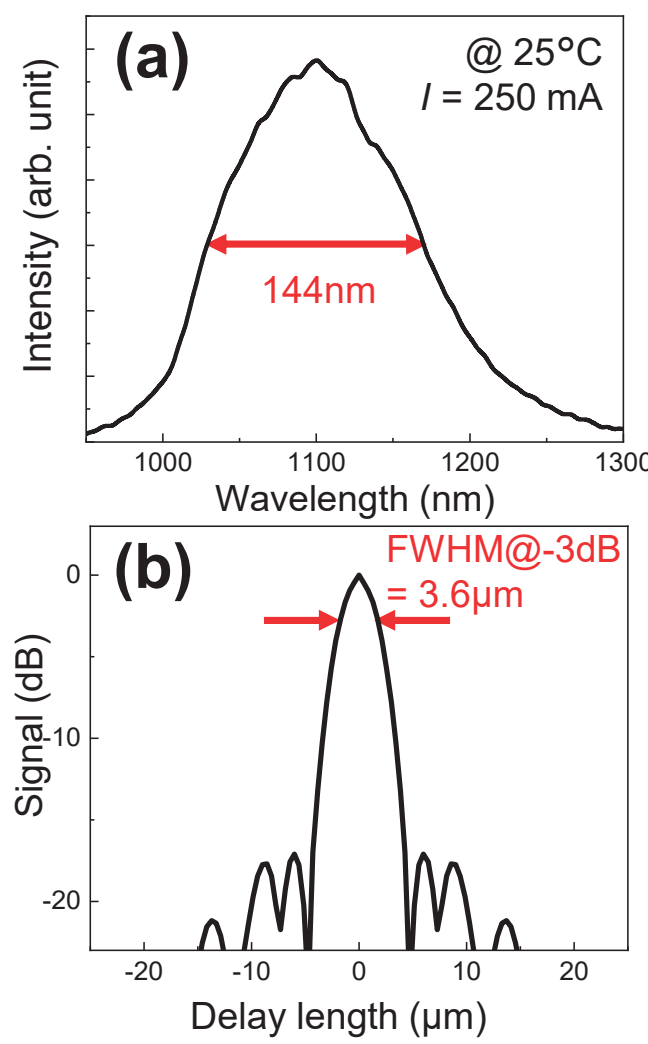

Fig. 4 (a) EL spectrum and (b) IFT spectrum obtained from the fabricated QD-SLD. 
OCT 光源として用いた場合, 空気中での光軸分解能が 約 $4 \mu \mathrm{m}$ と見込まれる結果になった28).

\section{QD-SLD による OCT イメージング}

作製した QD-SLDを，実際に OCT 光源として使用し た際の性能を評価するため, 作製したSLDチップをファ イバー結合モジュールとし， Fig. 5(a)に示すような SDOCT システム ${ }^{26)}$ に導入した。 ファイバーベースの干渉 計から得られた干渉光スペクトルを逆フーリ工変換して 光軸上の反射光強度の空間分布を取得した。

Fig. 5(b) に, 参照ミラーとの光路差約 $300 \mu \mathrm{m}$ の位置 にサンプルミラーを置いて取得した干渉光スペクトル (左)とフーリエ変換で得た反射光強度分布 (右)を示す. この反射光強度ピークが光源の PSFに相当し, その半 值幅から見積もられた光軸分解能は $4.2 \mu \mathrm{m}$ となった. これは Fig. 4(b)の自己相関関数から見積もった值と近 い值であり, 一般的な市販 SLDによる分解能 $(10 \sim 15 \mu \mathrm{m})$ を数倍程度上回る. また, PSF 形状は単峰 性であり，顕著なサイドローブが発生していないことか ら, 光源のスペクトル形状制御の有効性も確認できた。

テストサンプルとして厚さ約 $5 \mu \mathrm{m}$ の高分子(ニトロ セルロース)膜の断層画像を取得した。 Fig. 6 にQD-SLD 光源モジュールを用いて取得した OCT 画像と, 比較の ために同じサンプルを市販 SLD (分解能約 $14 \mu \mathrm{m}$ ) で取得 した OCT 画像を示す. 画像の縦軸が深さ (光軸) 方向で, 横軸が面内 (走査)方向である. 白い線状像が, サンプル の反射面を表している。市販 SLDによる画像(上)では 薄膜の表面と裏面の反射が分離されず，一本の太い帯の ように見えるのに対し，QD-SLD(下)では表面と裏面が 二本の細線として識別されている。プロファイルに示す ように二本の線の間隔は約 $7.3 \mu \mathrm{m}$ であり, 物理膜厚 $(5 \mu \mathrm{m})$ に屈折率(約 1.5$)$ を乗じた值に近い值が得られて いる. 以上から，QD-SLDを用いた OCT による $5 \mu \mathrm{m}$ 以

(a)

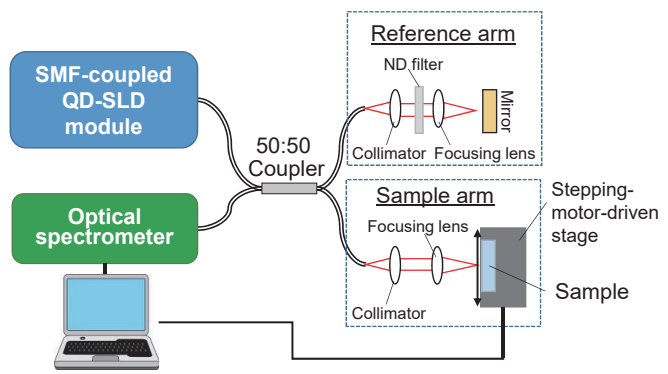

(b)
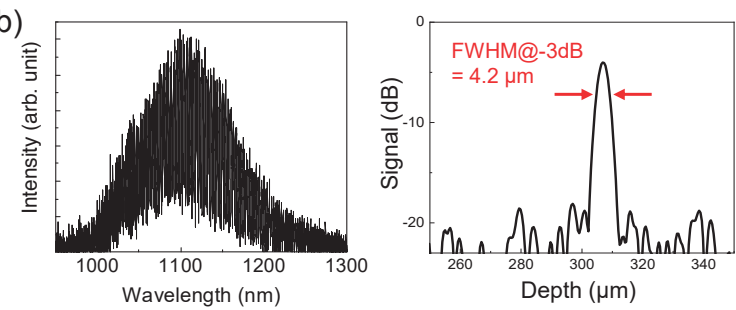

Fig. 5 (a)Schematic of the SD-OCT setup with the introduced QD-SLD. (b) Interference spectrum and PSF obtained using the QD-SLD.

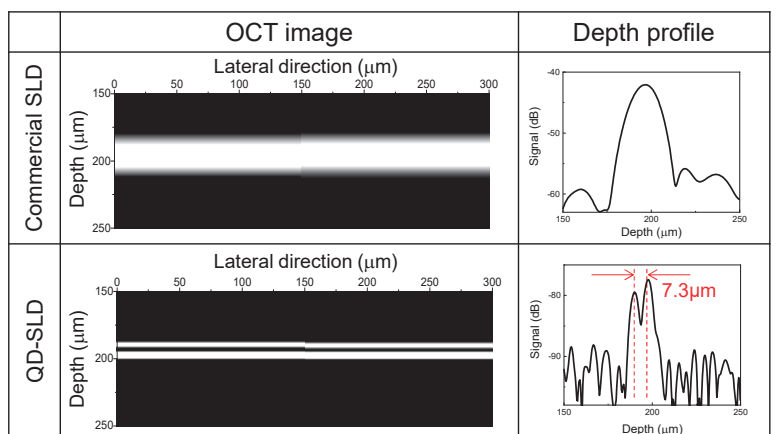

Fig. 6 Comparison of the OCT images of a $5-\mu \mathrm{m}$-thick film using a commercial SLD and the QD-SLD. Each depth profile was obtained at the left edge of the OCT image.

下の光軸分解能が示され，生体サンプルに扔いて単一細 胞の平均的なサイズである $5 \mu \mathrm{m}$ 以下の分解能が期待さ れる結果となった。

次に，擬似的な生体サンプルとして，植物サンプル (キャベッ葉)の OCT 画像取得を行った. Fig. 7(a) に示 すように, 光プローブをキャベッ葉の葉脈を横切るよう に走查し, 市販 SLD と QD-SLD で取得したOCT 画像 を比較した(Fig. 7(b))。 QD-SLDによる画像(下)の方が 解像度が向上しており, 葉脈内の管状構造や，葉の表面 の細胞壁がクリアに見えている。 QD-SLDを用いること で分解能が単細胞サイズ以下となり, 生体内部の微細な 細胞構造評価の可能性が示された.

\section{5. まとめと今後の展望}

自己組織化 InAs-QD を用いた広帯域 SLD 開発と, 高 分解能 OCT 光源への応用例を紹介した。波長制御され た QD を用いた SLD 光源により,一般的な SLD 光源を

(a)

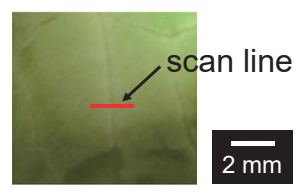

(b)

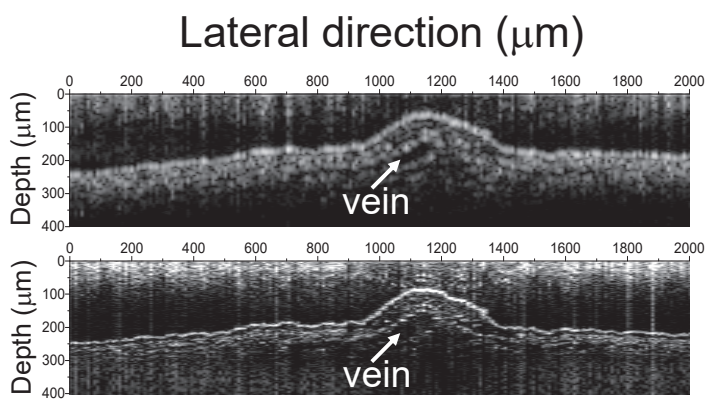

Fig. 7 (a) Plan-view optical microscopic image of a cabbage leaf under OCT observation. The lateral scan line is indicated by a solid line. (b) Comparison of the OCT images of the cabbage leaf acquired by the commercial SLD and QDSLD. 
上回る広帯域化と単峰性形状スペクトルが得られた。作 製した QD-SLD 光源を SD-OCT システムへ導入し, 約 $4 \mu \mathrm{m}$ の光軸分解能を持つ OCT 画像取得に成功した。 こ れらの結果から, QD-SLD は軽量・コンパクトな半導体 デバイスの特性を活かした高分解能 OCT 光源としての 利用が期待される。すなわち，光源の小型化により OCT システム全体がポータブルになるなどの展開が期 待できる。また, SLDは光学利得媒体としての利用が 可能であり, 外部共振器による波長掃引型レーザー光源 とすることで, SD-OCTのみならず SS-OCTへの応用も 可能である.

\section{謝 辞}

本研究は, JSPS科研費 $(25286052,16 \mathrm{H} 03858$, 16KK0130), テルモ生命科学振興財団, キヤノン財団, 文部科学省ナノテク PF 事業(NIMS 微細加工 PF)の支援 を受けて実施されました。 研究推進には, 和歌山大学大 学院生であった柴田弘, 保田拓磨, 林佑真, 山内翔各 氏, 英国 Glasgow 大学の Richard A. Hogg 教授, David T. D. Childs 講師, 物質 - 材料研究機構の大里 啓孝, 渡辺 英一郎, 池田 直樹, 杉本 喜正各氏, 日本電気株式 会社の大河内 俊介氏, 和歌山県立医科大学循環器内科 の赤阪隆史教授, 久保隆史准教授, シンクランド株式 会社の古城 健司, 及川陽一, 宮地 邦男各氏のご協力を 頂きました。この場を借りて厚く御礼申し上げます。

\section{参考文献}

1) M. S. Patterson, B. C. Wilson, and D. R. Wyman: Lasers in Med. Sci. 6 (1991) 379.

2) D. Huang, E. A. Swanson, C. P. Lin, J. S. Schuman, W. G. Stinson, W. Chang, M. R. Hee, T. Flotte, K. Gregory, C. A. Puliafito, and J. G. Fujimoto: Science 254 (1991) 1178.

3) M. E. Brezinski: Optical coherence tomography: principles and applications (Academic Press) (2006).

4) 春名 正光 : Med. Photon. 1 (2010) 29

5)W. Drexler and J. G. Fujimoto eds.: Optical Coherence Tomography Technology and Applications (Springer, Switzerland) (2015).

6) L. N. Kurbatov, S. S. Shakhidzhanov, L. V. Bystrova, V. V.
Karpukhin, and S. I. Kolenkova: Sov. Phys. Semicond. 4 (1971) 1739.

7)須郷 満, 柴田 泰夫, 吉村了行：レーザー研究 34 (2006) 505.

8) L. Goldstein, F. Glas, J. Y. Marzin, M. N. Charasse, and G. Le Roux: Appl. Phys. Lett. 47 (1985) 1099.

9) C. Akcay, P. Parrein, and J. P. Rolland: Appl. Opt. 41 (2002) 5256.

10) M. Wojtkowski, R. Leitgeb, A. Kowalczyk, T. Bajraszewski, and A.F. Fercher: J. Biomed. Opt. 7 (2002) 457.

11) S. H. Yun, G. J. Tearney, J. F. de Boer, N. Iftimia, and B. E. Bouma: Opt. Express 11 (2003) 2953

12) 安野 嘉晃：応用物理 75 (2006) 707.

13) 佐藤 学, 渡辺 裕輝：光学 37 (2008) 570 .

14) 湯浅哲也：Med. Imaging Tech. 29 (2011) 277.

15) A. F. Fercher, C. K. Hitzenberger, M. Sticker, E. Moreno-Barriuso, R. Leitgeb, W. Drexler, and H. Sattmann: Opt. Commun. 185 (2000) 57.

16) M. Ohmi and M. Haruna: Opt. Rev. 10 (2003) 478.

17) B. Bouma, G. J. Tearney, S. A. Boppart, M. R. Hee, M. E. Brezinski and J. G. Fujimoto: Opt. Lett. 20 (1995) 1486.

18) B. Povazay, K. Bizheva, A. Unterhuber, B. Hermann, H. Sattmann, A. F. Fercher, and W. Drexler, A. Apolonski, W. J. Wadsworth, J. C. Knight, and P. St. J. Russell, M. Vetterlein and E. Scherzer: Opt. Lett. 27 (2002) 1800.

19) H. Kawagoe, S. Ishida, M. Aramaki, Y. Sakakibara, E. Omoda, H. Kataura, and N. Nishizawa: Biomed. Opt. Express 5 (2014) 932.

20) Z. Z. Sun, D. Ding, Q. Gong, W. Zhou, B. Xu, and Z. G. Wang: Optical Quant. Electron. 31 (1999) 1235.

21) M. Rossetti, A. Markus, A. Fiore, L. Occhi, and C. Velez: IEEE Photon. Technol. Lett. 17 (2005) 540.

22) Z. Y. Zhang, R. A. Hogg, X. Q. Lv, and Z. G. Wang: Adv. Opt. Photonics 2 (2010) 201.

23) M. Tsuda, T. Inoue, T. Kita, and O. Wada: Phys. Status Solidi C 8 (2011) 331.

24) N. Ozaki, T. Yasuda, S. Ohkouchi, E. Watanabe, N. Ikeda, Y. Sugimoto, and R. Hogg: Jpn. J. Appl. Phys. 53 (2014) 04EG10.

25) S. Chen, W. Li, Z. Zhang, D. Childs, K. Zhou, J. Orchard, K. Kennedy, M. Hugues, E. Clarke, I. Ross, O. Wada, and R. Hogg: Nanoscale Res. Lett. 10 (2015) 340.

26) H. Shibata, N. Ozaki, T. Yasuda, S. Ohkouchi, N. Ikeda, H. Ohsato, E. Watanabe, Y. Sugimoto, K. Furuki, K. Miyaji, and R. A. Hogg: Jpn. J. Appl. Phys. 54 (2015) 04DG07.

27) N. Ozaki, D. T. D. Childs, J. Sarma, T. S. Roberts, T. Yasuda, H. Shibata, H. Ohsato, E. Watanabe, N. Ikeda, Y. Sugimoto, and R. A. Hogg: J. Appl. Phys. 119 (2016) 083107.

28) N. Ozaki, S. Yamauchi, Y. Hayashi, E. Watanabe, H. Ohsato, N. Ikeda, Y. Sugimoto, K. Furuki, Y. Oikawa, K. Miyaji, D. T. D. Childs, and R. A. Hogg: J. Phys. D: Appl. Phys. 52 (2019) 225105.

29) A. F. Forrest, M. Krakowski, P. Bardella, and M. A. Cataluna: Opt. Express 27 (2019) 10981.

30) K. Nishi, H. Saito, S. Sugou, and J.-S. Lee: Appl. Phys. Lett. 74 (1999) 1111. 